\title{
PHẪU THUẬT NỘI SOI TOÀN BỘ VÁ THÔNG LIÊN NHĨ TRÊN BỆNH NHÂN GIÁN ĐOẠN TĨNH MẠCH CHỦ DƯớI: NHÂN 1 TRƯờNG HỢP
}

\author{
Đặng Quang Huy*, Nguyễn Minh Ngoc**
}

Đơn nguyên phẫu thuật tim ít xâm lấn, Trung tâm phẫu thuật tim mạch, bệnh viện Tim Hà Nội, 92 Trần Hưng Đạo, Hoàn Kiếm, Hà Nội.

\section{TÓM TẮT}

Bất thường gián đoạn tĩnh mạch chủ dưới là yếu tố gây trở ngại cho việc điều trị đóng lỗ thông liên nhĩ. Chúng tôi báo cáo 01 ca lâm sàng bệnh nhân nữ 44 tuổi có thông liên nhĩ lỗ thứ hai và gián đoạn tĩnh mạch chủ dưới đã được điều trị thành công bằng phương pháp phẫu thuật nội soi toàn bộ, tim đập.

\section{I. ĐẶT VẤN ĐỀ}

Thông liên nhĩ lỗ thứ hai là một bệnh lý tim bẩm sinh thường gặp, với tỉ lệ khoảng 6-10\% các bệnh tim bẩm sinh.[1] Phương pháp điều trị chủ yếu hiện nay là phương pháp đóng thông liên nhĩ bằng can thiệp bít dù qua da hoặc phẫu thuật vá thông liên nhĩ. Hiện nay, với sự phát triển của phẫu thuật ít xâm lấn, phẫu thuật vá thông liên nhĩ đã có thể thực hiện bằng phương pháp nội soi toàn bộ. [2]

Đối với bệnh nhân thông liên nhĩ có kèm theo bất thường gián đoạn tĩnh mạch chủ dưới, điều trị can thiệp bít dù qua da gặp nhiều khó khăn và có nguy cơ cao. Phẫu thuật kinh điển cưa xương ức thường là lựa chọn hàng đầu đối với những ca bệnh này. Tuy nhiên, với một cách tiếp cận mới, bệnh lý thông liên nhĩ kết hợp với gián đoạn tĩnh mạch chủ dưới có thể được điều trị bằng phương pháp phẫu thuật nội soi toàn bộ, tim đập.
Chúng tôi báo cáo một ca lâm sàng bệnh nhân có thông liên nhĩ kết hợp với gián đoạn tĩnh mạch chủ dưới, đã được điều trị bằng phương pháp này.

\section{BÁO CÁO CA LÂM SÀNG}

Bệnh nhân nữ 44 tuổi, cân nặng 43kg, nhập viện vì khó thở khi gắng sức. Trên siêu âm tim trước mổ có hình ảnh lỗ thông liên nhĩ thứ phát đường kính $22 \mathrm{~mm}$, shunt trái - phải, gờ $\mathrm{TMC}$ trên $8 \mathrm{~mm}$, gờ $\mathrm{TMC}$ dưới $6 \mathrm{~mm}$, gờ van hai lá $17 \mathrm{~mm}$, gờ xoang vành $17 \mathrm{~mm}$, đường kính tâm trương thất phải $29 \mathrm{~mm}$, áp lực động mạch phổi $42 \mathrm{mmHg}$. Van hai lá và van ba lá hở rất nhẹ.Điện tim nhịp xoang.

Bệnh nhân đã được chỉ định bít dù thông liên nhĩ qua da, trong quá trình can thiệpnghi ngờ có bất thường tĩnh mạch chủ dưới do không luồn được dây dẫn nên ngừng thủ thuật. Bệnh nhân sau đó được chụp cắt lớp vi tính phát hiện gián đoạn tĩnh mạch chủ dưới, sau hai tĩnh mạch thận.Máu từ tĩnh mạch chủ dưới đổ về tĩnh mạch bán đơn, sau đó tiếp nối tĩnh mạch bán đơn - tĩnh mạch đơn ở phía sau động mạch chủ bụng, và đổ về tĩnh mạch chủ trên. Phần trên gan của tĩnh mạch chủ dưới đổ trực tiếp về nhĩ phải.

* Bệnh viện Tim Hà Nội

Người chịu trách nhiệm khoa học: ThS. Đặng Quang Huy Ngày nhận bài: 01/05/2019 - Ngày Cho Phép Đăng: 15/05/2019

Phản Biện Khoa học: PGS.TS. Đặng Ngọc Hùng GS.TS. Lê Ngoc Thành 


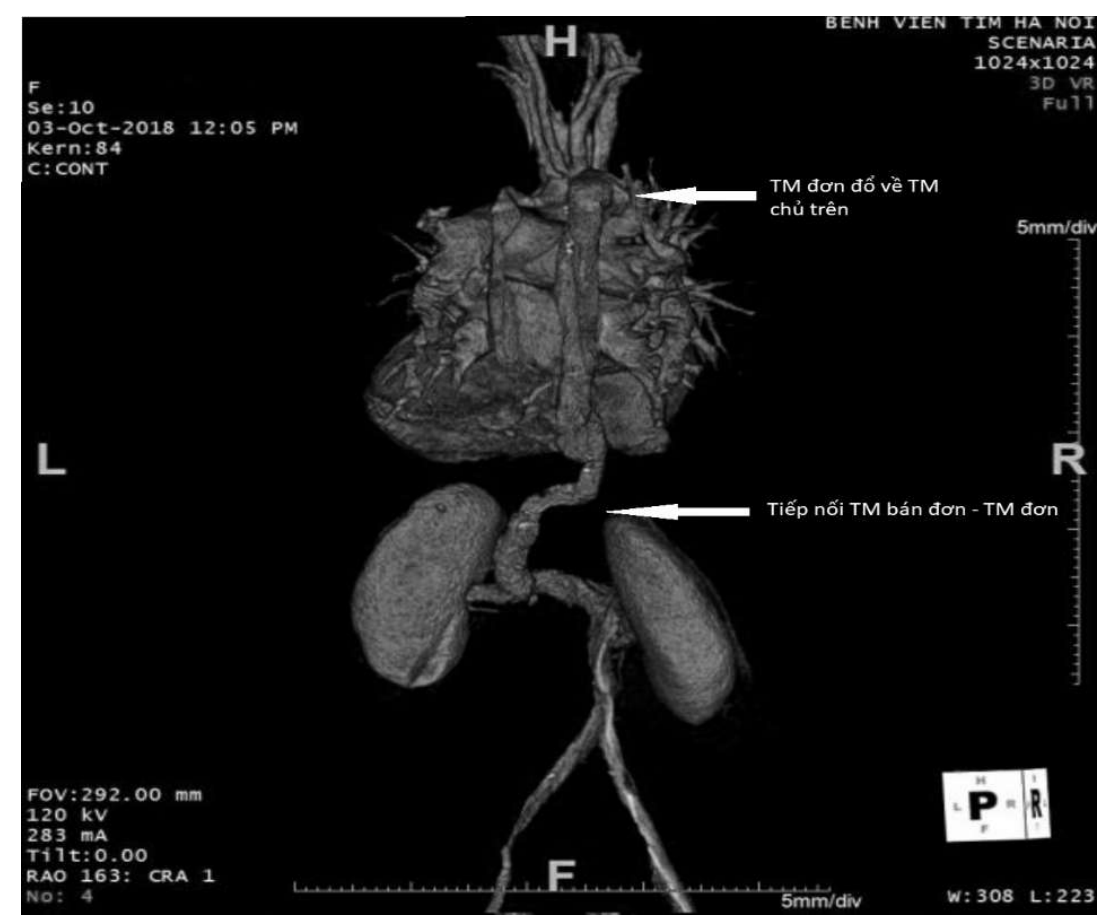

Hình 1: Hình ảnh gián đoạn TM chủ dưới trên chụp cắt lớp vi tính

Bệnh nhân đã được hội chẩn và quyết định đóng lỗ thông liên nhĩ bằng phương pháp phẫu thuật nội soi toàn bộ tim đập.

Trong mổ, bệnh nhân được kê tư thế nghiêng trái 30 độ. Thiết lập tuần hoàn ngoài cơ thể qua mạch ngoại vi: đặt cannula ĐM đùi gián tiếp qua đoạn mạch số 8 (B. Braun Uni-Graft), và đặt cannula $T M$ chủ trên và dưới qua $T M$ cảnh trong phải và $\mathrm{TM}$ đùi phải theo phương pháp Seldinger. Sử dụng cannula $\mathrm{TM}$ chủ trênvà cannula TM chủ dưới kích cỡ21Fr (Medtronic Bio-medicus). Cannula TM chủ dưới chỉ được đưa vào sâu khoảng $20 \mathrm{~cm}$, tương ứng với phần gián đoạn của $\mathrm{TM}$ chủ dưới khảo sát trên phim chụp cắt lớp. Đối với phần trên gan của $\mathrm{TM}$ chủ dưới đổ về vào nhĩ phải, chúng tôi quyết định đặt 01 cannula tĩnh mạch kích cỡ 16Fr (Medtronic DLP) trực tiếp vào tĩnh mạch gan qua một lỗ trocar trên thành ngực.
Tiến hành chọc 05 lỗ trocar qua thành ngực.

- 01 1ỗ 10mm cho tay phẫu thuật chính (tay phải)

- 01 lỗ 5mm cho camera nội soi

- 01 lỗ $5 \mathrm{~mm}$ cho tay phẫu thuật phụ (tay trái)

- 01 1ỗ $5 \mathrm{~mm}$ cho dụng cụ hút máu về máy THNCT

- 01 lỗ $5 \mathrm{~mm}$ cho cannula tĩnh mạch đặt trực tiếp.

Bơm $\mathrm{CO} 2$ vào khoang màng phổi với lưu lượng 11/phút. Chạy máy THNCT toàn bộ lưu lượng, khảo sát giải phẫu thấy tĩnh mạch đơn giãn lớn, đổ trực tiếp vào tĩnh mạch chủ trên. Đoạn trên gan của tĩnh mạch chủ dưới đổ trực tiếp vào nhĩ phải. Tiến hành đặt cannula trực tiếp vàođoạn trên gan của TM chủ dưới qua nhĩ phải. Luồn dây thắt $\mathrm{TM}$ chủ trên và $\mathrm{TM}$ chủ dưới. Mở dọc nhĩ phải, khâu treo bộc lộ lỗ 
thông liên nhĩ. Trong quá trình mổ tim vẫn đập, máu về nhĩ phải qua xoang vành và các tĩnh mạch phụ được hút về qua dụng cụ hút chọc qua lỗ trocar ở thành ngực. Thông liên nhĩ lỗ thứ haicó kích thước $15 \times 20 \mathrm{~mm}$, gờ $\mathrm{TM}$ chủ dưới mỏng. Không có bất thường $\mathrm{TM}$ phổi và xoang vành. Tiến hành đóng lỗ thông bằng miếng vá nhân tạo (AesculapNeuropatch), khâu vắt bằng chỉ 4-0 có tăng cường bằng các mũi rời. Sau khi đóng lỗ thông tiến hành đóng nhĩ phải hai lớp, sau đó rút cannula tĩnh mạch gan và khâu tăng cường vị trí đặt cannula. Kiểm tra cầm máu, đặt các dẫn lưu, rút các cannula động tĩnh mạch và đóng vết mổ.

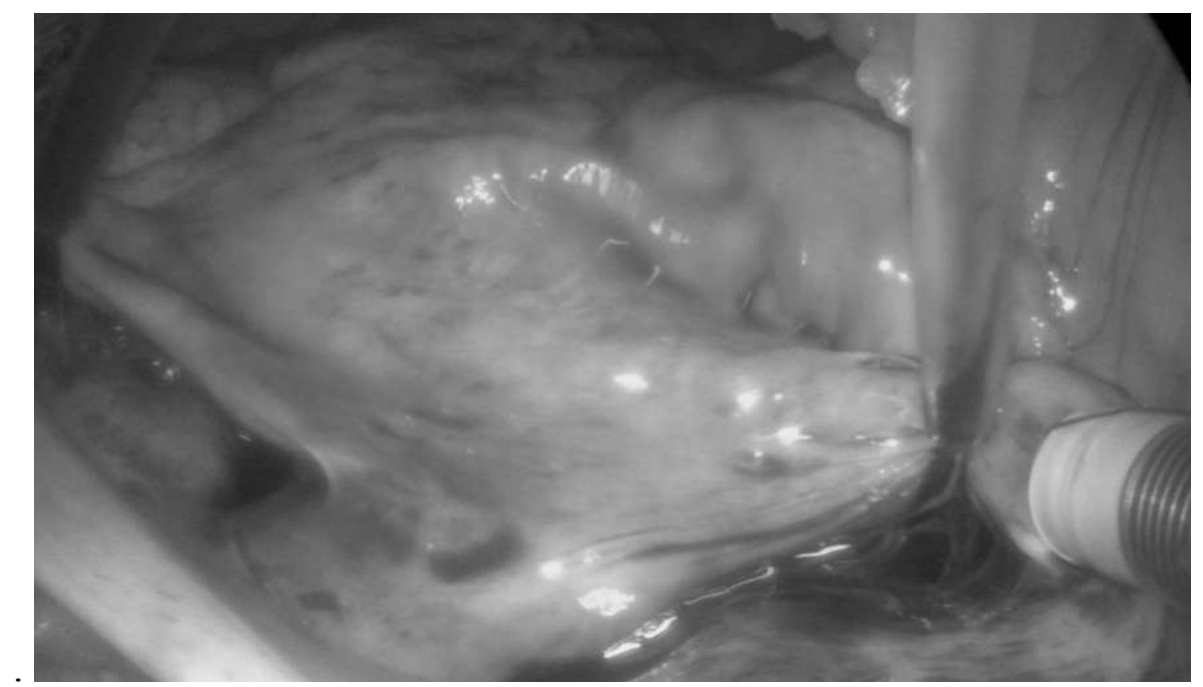

Hình 2: Cannula tĩnh mạch đặt trục tiếp vào phần trên gan của tĩnh mạch chủ dưới đổ vào nhĩ phải

Thời gian phẫu thuật là 180 phút, thời gian chạy máy THNCT là 76 phút. Bệnh nhân về hồi sức được rút nội khí quản sau 18 giờ, không có biến chứng thần kinh do tắc mạch khí, chảy máu, suy tim hay nhiễm trùng. Bệnh nhân nằm hồi sức 02 ngày, ra viện sau 05 ngày. Trước ra viện siêu âm tim không có lỗ thông tồn lưu, chức năng tim tốt. Bệnh nhân ra viện với cơ năng ổn định, không cần sử dụng thuốc giảm đau.

Sau mổ 1 tháng và 3 tháng, bệnh nhân khám lại ổn định, không có biến chứng

\section{BÀN LUẬN}

Tại các trung tâm tim mạch trên thế giới hiện nay, điều trị đóng thông liên nhĩ bằng can thiệp vẫn là lựa chọn hàng đầu. Tuy nhiên nghiên cứu của Tomar, $\mathrm{M}$. và cs cho thấy về lâu dài bít dù thông liên nhĩ có tỉ lệ nhất định các biến chứng như loét cơ tim, dị ứng kim loại, viêm nội tâm mạc nhiễm khuẩn,...[3] Phẫu thuật đóng thông liên nhĩ thường được chỉ định trong các trường hợp lỗ thông liên nhĩ không bịt dù được, như thông liên nhĩ quá lớn, nhiều lỗ thông, gờ ngắn, có hở van hai lá, van ba lá kèm theo... Phẫu thuật kinh điển vẫn là phẫu thuật cưa toàn bộ xương ức, tuy nhiên có nhược điểm là gây đau nhiều, có thể có biến chứng nhiễm trùng hay biến dạng xương ức, ảnh hưởng đến thẩm mỹ và chất lượng cuộc sống của bệnh nhân.[4] Phẫu thuật ít xâm lấn và 
phẫu thuật nội soi toàn bộ (có hoặc không có sự hỗ trợ của Robot) khắc phục được một phần hoặc toàn bộ những nhược điểm đó của phẫu thuật kinh điển, nên ngày càng được áp dụng rộng rãi và chứng tỏ vai trò của mình trong điều trị thông liên nhĩ.

Gián đoạn tĩnh mạch chủ dưới là một bất thường hiếm gặp, biểu hiện bởi sự mất đoạn qua gan (hepatic segment) của tĩnh mạch chủ dưới.Tĩnh mạch chủ dưới bị gián đoạn ở sau lỗ đổ vào của hai tĩnh mạch thận. Máu nửa dưới cơ thể đổ về tĩnh mạch đơn, sau đó về tim qua tĩnh mạch chủ trên. Đoạn trên gan của tĩnh mạch chủ dưới đổ về tâm nhĩ phải ở vị trí bình thường. Trên bệnh nhân thông liên nhĩ có kèm theo gián đoạn tĩnh mạch chủ dưới, việc điều trị bằng phương pháp bít dù qua da gặp nhiều khó khăn.[5]

Một số tác giả đã báo cáo các trường hợp can thiệp bít dù thành công, với đường vào là tĩnh mạch cảnh trong, tĩnh mạch gan hoặc tĩnh mạch đùi có siêu âm thực quản hỗ trợ.[5-7] Tuy nhiên nhược điểm của phương pháp bít dù đối với nhóm bệnh nhân này là kĩ thuật khó, mất nhiều thời gian, có nhiều nguy cơ trong quá trình can thiệp. Bên cạnh đó về lâu dài có thể có các biến chứng muộn do dụng cụ bít dù thông liên nhĩ.Trong những trường hợp này, cách thức điều trị được ưu tiênvẫn là phẫu thuật đóng thông liên nhĩ bằng đường mổ kinh điển.

Hiện nay tại Việt Nam, nhiều trung tâm đã áp dụng kĩ thuật đóng thông liên nhĩ bằng phẫu thuật nội soi toàn bộ, tim đập. Phương pháp nội soi 4 lỗ được mô tả bởi Dang, Q.H. và cs, có ưu điểm là an toàn, chi phí thấp trong khi vẫn mang lại hiệu quả điều trị và thẩm mỹ tương đương với phẫu thuật nội soi Robot hỗ trợ.[4]
Theo tác giả Dang Q.H, trong phẫu thuật nội soi toàn bộ vá thông liên nhĩ, tuần hoàn ngoài cơ thể ngoại vi được thiết lập với cannula TM đùi và $\mathrm{TM}$ cảnh trong. Để đảm bảo phẫu trường sạch máu, máu tĩnh mạch được hút về máy THNCT với áp lực âm hỗ trợ. TM chủ trên được luồn dây thắt, và máu về qua xoang vành được hút về bằng dụng cụ hút đưa qua lỗ trocar số 4 trên thành ngực. Trong trường hợp bệnh nhân của chúng tôi, khi áp dụng phương pháp nội soi toàn bộ, việc thiết lập cannula tĩnh mạch đặt vào $\mathrm{TM}$ đùi và TM cảnh trong không đảm bảo được phẫu trường sạch máu, do không đưa được cannula TM chủ dưới vào trong nhĩ phải, khiến cho khi thắt $\mathrm{TM}$ chủ trên lượng máu về tâm nhĩ phải từ $\mathrm{TM}$ chủ dưới đoạn trên gan sẽ đổ về phẫu trường, gây khó khăn cho phẫu thuật, trong khi dụng cụ hút không đảm bảo hút sạch máu để bộc lộ lỗ thông, hơn nữa hút với áp lực lớn có thể gây tan máu. Để giải quyết vấn đề này, chúng tôi quyết định đưa thêm 1 cannula tĩnh mạch qua 1 lỗ trocar thứ 5 trên thành ngực, đặt trực tiếp vào $\mathrm{TM}$ chủ dưới đoạn trên gan, cộng với việc luồn dây thắt $\mathrm{TM}$ chủ dưới, đảm bảo máu từ TM chủ dưới đoạn trên gan không về nhĩ phải trong suốt quá trình mổ, qua đó bộc lộ tốt lỗ thông liên nhĩ để vá.

Tim đập trong suốt quá trình mổ. Để tránh biến chứng tắc mạch khí, chúng tôi bơm khí $\mathrm{CO} 2$ vào khoang lồng ngực với lưu lượng 11/phút, đặt bệnh nhân ở tư thế đầu thấp và duy trì huyết áp động mạch trên $70 \mathrm{mmHg}$. Uu điểm của phương pháp vá thông liên nhĩ tim đập là bảo vệ cơ tim, hạn chế biến chứng suy tim do tổn thương tái tưới máu, bên cạnh đó việc duy trì tim đập có thể giúp phẫu thuật viên phát hiện sớm các biến chứng về dẫn truyền gây ra do kĩ thuật vá lỗ thông.[4] 
So với các cuộc mổ vá thông liên nhĩ nội soi toàn bộ thông thường, trong trường hợp bệnh nhân được báo cáo, thủ thuật đặt cannula tĩnh mạch trực tiếp vào $\mathrm{TM}$ chủ dưới đoạn trên ganqua lỗ trocar thứ 5 trên thành ngực là một thủ thuật không phức tạp, an toàn và không làm kéo dài thời gian cuộc mổ. Thời gian mổ (da đến da) của chúng tôi khoảng 180 phút và thời gian chạy máy chỉ 76 phút. Sau mổ, thời gian thở máy và nằm viện ngắn, hiệu quả điều trị cũng như hiệu quả thẩm mĩ vẫn được đảm bảo.

\section{IV.KẾT LUẬN}

Bệnh lý thông liên nhĩ kèm theo gián đoạn tĩnh mạch chủ dưới là một bệnh lý rất hiếm gặp. Can thiệp bịt dù thông liên nhĩ trong trường hợp này dù khả thi nhưng gặp khó khăn về mặt kỹ thuật và nhiều nguy cơ. Phương pháp phẫu thuật nội soi toàn bộ vá thông liên nhĩ, tim đập và đặt cannula tĩnh mạch trực tiếp là phương pháp điều trị triệt để,an toàn vàhiệu quả.

\section{TÀI LIỆ THAM KHẢO}

1. van der Linde, D., et al., Birth prevalence of congenital heart disease worldwide: a systematic review and meta- analysis. J Am Coll Cardiol, 2011. 58(21): p. 2241-7.

2. Gao, C., et al., Totally endoscopic robotic atrial septal defect repair on the beating heart. Heart Surg Forum, 2010. 13(3): p. E155-8.

3. Tomar, M., et al., Intermediate and long-term followup of percutaneous device closure of fossa ovalis atrial septal defect by the Amplatzer septal occluder in a cohort of 529 patients. Ann Pediatr Cardiol, 2011. 4(1): p. 22-7.

4. Dang, Q.H., et al., Totally Endoscopic Cardiac Surgery for Atrial Septal Defect Repair on Beating Heart Without Robotic Assistance in 25 Patients. Innovations (Phila), 2017. 12(6): p. 446-452.

5. Truong, Q.B., et al., Percutaneous atrial septal defect closure through femoral and transjugular approaches in patients with interrupted inferior vena cava. J Cardiol Cases, 2018. 18(3): p. 106-109.

6. Lowry, A.W., R.H. Pignatelli, and H. Justino, Percutaneous atrial septal defect closure in a child with interrupted inferior vena cava: successful femoral venous approach. Catheter Cardiovasc Interv, 2011. 78(4): p. 590-3.

7. Seshagiri, R.D., A.N. Patnaik, and B. Srinivas, Percutaneous closure of atrial septal defect via transjugular approach with Blockaid device in a patient with interrupted inferior vena cava. Cardiovasc Interv Ther, 2013. 28(1): p. 63-5. 